\title{
O FENÔMENO GLASS CEILING E O ACESSO À INFORMAÇÃO: ESTUDO SOBRE BARREIRAS INVISÍVEIS IMPOSTAS ÀS MULHERES NO TRABALHO
}

Beatriz Benedito de Oliveira

Luana Maia Woida

Graduanda em Tecnologia em Gestão Empresarial - Faculdade de

Tecnologia - Garça. E-mail: beatriz.benedito01@fatec.sp.gov.br

\begin{abstract}
Professora de Tecnologia em Gestão Empresarial - Faculdade de Tecnologia - Garça. Doutora em Ciência da Informação na Universidade Estadual Paulista - Júlio de Mesquita Filho. Mestre em Ciência da Informação na Universidade Estadual Paulista - Júlio de Mesquita Filho e Bacharel em Administração pela Universidade Estadual de Londrina. E-mail: luanamwoida@yahoo.com.br
\end{abstract}

\section{RESUMO}

O artigo discute essencialmente sobre a metáfora Glass Ceiling ou Teto de Vidro, segundo o qual, existem barreiras invisíveis que dificultam o acesso das mulheres aos cargos de maiores salários e responsabilidades, ocasionando assim, a segregação hierárquica (ou vertical na estrutura organizacional) (JARMON, 2014). Ao investigar a respeito do teto de vidro, percebe-se que são várias as condições que levam a sua existência, incluindo-se a falta de acesso à informação, uma vez que o acesso à informação ajuda no combate à discriminação de gênero (PAES, 2016). O resultado do não acesso à informação produz decisões mal alicerçadas e desempenhos desastrosos. Quanto à formação e aos níveis educacionais, sabe-se não se tratar mais como uma das fragilidades no que tange à capacidade de assumir e desempenhar o trabalho, uma vez que as mulheres se tornaram maioria nas universidades. Números confirmados entre aqueles que se graduam. Sabe-se que a cultura machista ainda é encontrada dentro das empresas, sendo uma barreira já conhecida e parte da agenda de enfrentamento das mulheres trabalhadoras, representado pelo fato de não acessarem as redes de relações informais dos homens no trabalho (AKPINARSPOSITO, 2013, p.494). Contudo, existem mais fatores além desses que não tão claramente percebidos e que podem atuar na dificuldade de ascensão da mulher na hierarquia das empresas. Neste sentido, a investigação objetiva responder a seguinte pergunta: o teto de vidro é um fenômeno associado à ausência de acesso à informação pelas mulheres? Sendo assim, o fulcro consiste em indicar o que 
determina a existência deste fenômeno dentro dos espaços corporativos, destacando a falta de acesso à informação como um dos elementos que produzem um contexto de dificuldades para a atuação da mulher trabalhadora. Desta forma, esta pesquisa traz como finalidade a conscientização das empresas de que os mecanismos de exclusão, que estão inseridos dentro e fora do contexto organizacional prejudicam o crescimento profissional das mulheres e, consequentemente, um melhor desempenho. Além disso, o estudo também possibilita a contribuição de novas hipóteses para o conhecimento científico e literatura nacional, principalmente, com relação as pesquisas que seguem como fulcro a investigação de mulheres nos espaços executivos e sua participação direta no fluxo de informação. Para a execução desta pesquisa exploratória e descritiva, adotou-se como procedimentos a aplicação de questionários no formato da escala de likert mulheres que exerciam ou exercem funções em níveis hierárquicos mais elevados, as quais foram submetidas à questionamentos sobre o acesso à informação, porém de maneira comparativa à percepção que elas detêm sobre o acesso realizado pelos trabalhadores homens. Assim, as informações coletadas sugerem que as mulheres sofrem preconceitos no ambiente trabalho, e precisam enfrentar barreiras nem sempre tão invisíveis assim, pois atos de assédio moral foram relatados. Contudo, a associação entre o teto de vidro e a falta de acesso à informação está presente na literatura, mas não foi verificada entre as participantes da pesquisa.

PALAVRAS-CHAVE: Fenômeno Teto de Vidro. Mecanismos de Exclusão. Barreira Invisível. Acesso à informação.

\title{
GLASS CEILING PHENOMENON AND ACCESS TO INFORMATION: STUDY ON INVISIBLE BARRIERS IMPOSED AT WOMEN AT WORK
}

\begin{abstract}
This paper discusses the Glass Ceiling metaphor, according to which, it allows the construction of invisible barriers that hinder the access of the women to positions with higher salaries and responsibilities, thus, causing hierarchical or vertical segregation in the organizational structure. When investigating about the glass ceiling, it is noticed that there are several conditions that lead to this fact, such as lack of accessing information. The non-access to information produces poorly-based decisions and disastrous performances. About training and educational levels, it is known that it is no longer treated as one of the weaknesses in the ability to take over and perform the job, since women have become a majority in universities in Brazil. It is known that the machismo culture is still found within the companies, being a well-known barrier. However, there are more factors besides these, which are not so clearly perceived and that can act in the difficulty of ascending women in the companies' hierarchy. In this sense, this research aimed to answer the following question: could be glass ceiling a phenomenon associated with the lack of access to information? Thus, the fulcrum consists of indicating what determines the existence of this phenomenon within
\end{abstract}


corporate spaces, highlighting the lack of access to information as one of the factors that produce difficulties for working women. Furthermore, this research aims to raise the awareness of companies that the exclusion and sexist biases, which are inside and outside of organizational context, hinder the professional growth of women and, consequently, a better performance of the organizations. In addition, this analysis also makes possible to contribute with new hypotheses to scientific knowledge, especially in relation to research about women in executive spaces and their direct participation in the flow of information. For the execution of this exploratory and descriptive research, it was adopted as procedures the application of questionnaires in the format of the likert scale women who exercised or performed functions at higher hierarchical levels, which were submitted to questions about access to information, but of comparative to their perception of male workers' access. Thus, the information collected suggests that women suffer from prejudices in the work environment, and must face barriers that are not always so invisible, as acts of bullying have been reported. However, the association between glass ceiling and lack of access to information is present in the literature, but was not verified among the participants of the research.

KEYWORDS: Glass Ceiling. Exclusion. Invisible Barrier. Access to information.

\section{INTRODUÇÃO}

As organizações vivenciam um contexto econômico, composto por concorrência e situações inesperadas, pois são diversos ambientes que a influenciam e proporcionam constantes transformações em escala local e mundial. Desta forma, a adaptação das empresas neste contexto de modificações econômicas é fundamental para a sobrevivência da organização no mercado (YAFUSHI, 2015, p.16). Neste sentido, muitas empresas utilizam a informação como recurso estratégico para adequação as alterações no ambiente. Sendo assim, a utilização da informação é subsídio para a competitividade e sobrevivência das organizações no mercado atual.

Diante desse contexto, as condições de acesso e manejo da informação são um alicerce para indivíduos que atuam em diferentes níveis hierárquicos nas organizações, uma vez que a informação deve fluir, de preferência evitando barreiras para acessa-la e usa-la. Seguindo essa linha de raciocínio, compreende-se que a disseminação da informação é uma parte do manejo da informação e que permite a existência do fluxo de informação, podendo-se defini-la como divulgação ou propagação da informação (BARROS, 2003, p.56). Por sua vez o fluxo da informação é defendido por Inomata e Varvakis (2016, p.294) como uma informação que percorre um ciclo, cuja dinâmica pode ser afetada por barreiras informacionais, compreendidas como "[...] ruídos no processo informacional, entendidos como problemas que impedem a 
obtenção da informação”. Além disso, Inomata e Varvakis (2016, p.152) sugerem doze barreiras que afetam diretamente a busca e o acesso à informação, merecendo destaque a falta de diálogo, constituindo-se um produto do ambiente sociocultural e coincidindo com uma das categorias de barreiras de comunicação da informação, que é a cultura organizacional. De acordo com Starec (2012), a falta de estímulo à comunicação, entendida como um resultado da cultura organizacional, resulta no não acesso à informação.

Somam-se aos problemas de manejo da informação, outros de ordem também sociocultural nas organizações, pois estas propagam uma reprodução de desigualdades e discriminações advindas da sociedade na qual estão imersas, e que implicam na falta de comunicação e na inacessibilidade da informação. Paes (2016) expõe que o acesso à informação pública, realizado pela mulher deveria ser garantido, mas ainda sofre obstáculos. No entanto, a autora defende que o acesso em si poderia promover o combate à discriminação de gênero, pois garantiria às mulheres subsídio para atuarem conhecendo melhor os próprios direitos. Nesse caso, a situação de discriminação quanto ao acesso à informação não é restrita à informação pública sobre a saúde da mulher, uma vez que as organizações reproduzem os impedimentos em relação ao acesso à informação no âmbito laboral.

Para Oyelup (2012), o acesso à informação instrumentaliza a mulher com informações sobre suas condições de saúde e também para os negócios. Os limites de acesso à informação são dados pelo contexto cultural, com grande participação da religião para essa condição.

De acordo com Jamon (2014, p.101), a exclusão política dos grupos, especialmente os formados por homens ("bons e velhos meninos" ou "clube do bolinha"), conduz à exclusão da comunicação e ao acesso a informações que percorrem o fluxo, levando ao impedimento de mobilidade na organização.

Jamon (2014, p.101) argumenta que o ato de ignorar as ideias das mulheres é uma das práticas para impedi-las de participar da comunicação, além disso, "Alguém ter o direito de acessar a informação e aprender mais sobre a organização é impossibilitado pelos canais regulares de comunicação", isto é, uma parte importante das informações acessadas não está disponível nos meios formais de comunicação, integrando a esfera dos grupos informais, o que dificulta em muito o percurso laboral da mulher, pois esta se localiza em uma condição de exclusão social dentro das empresas. Sobre essa prática de discriminação, Akpinar-Sposito (2013) acredita que existem barreiras de gênero no ambiente de trabalho, verificadas, por exemplo, no fato da mulher não acessar as redes informais de comunicação em função das 
atividades que ocupa, as quais em geral, não possuem características "masculinas". Dessa forma, entende-se se constituir em uma ciclo de impedimentos de acesso à informação e de mobilidade entre postos de trabalho nas organizações.

Como exemplo de desigualdade, a baixa representatividade das mulheres em cargos hierarquicamente superiores. Segundo dados divulgados pelo Instituto Ethos (2015) em 2010, apenas $13,7 \%$ das mulheres ocupavam o quadro executivo. No entanto, de acordo com pesquisa realizada em 2015 13,6\% das executivas estavam neste cargo, sendo que, 86,4\% dos homens representavam a diretoria das organizações entrevistadas.

A pesquisa do Instituto Ethos (2015) revela ainda que nos conselhos de administração $11 \%$ das mulheres eram conselheiras e $89 \%$ dos homens exerciam esta atividade. Na gerência $31,3 \%$ eram mulheres e $68,7 \%$ eram homens, por outro lado, até o cargo mais baixo de liderança ocorre a insuficiência de mulheres exercendo, pois, na supervisão 38,8\% eram supervisoras e 61,2\% eram homens ocupados nesta atividade. Este afunilamento refere-se à segregação hierárquica (ou vertical) baseada em gênero na estrutura organizacional, segundo a qual, as mulheres têm menos oportunidades de crescimento dentro da pirâmide corporativa, em comparação aos homens (YANNOULAS, 2002, p.16). Tal situação ocasiona a subrepresentação das mulheres em cargos de maiores responsabilidades e remunerações (STEIL, 1997; BOTELHO; MACEDO; FIALHO, 2010; BERNARDI; NEVES, 2015; CAPELLIN, 2008). Desse modo, compreende-se que o efeito 'Glass Ceiling' ou Teto de Vidro promove barreiras invisíveis que interrompem a ascensão das trabalhadoras a alta cúpula organizacional.

O uso da informação possibilita o nivelamento entre "a forma de pensar e agir das altas hierarquias organizacionais" (DANTAS, 2006). Para que isso ocorra, o acesso à informação deve ser permitido, incentivado e praticado por aqueles que estão na alta cúpula organizacional. Nesse caso, para que as mulheres acessem as informações precisam ultrapassar obstáculos, tal como a resistência que ainda se percebe a respeito de se ter uma 'mulher' como chefe.

A resistência dos pares de trabalho é sentida em ideias e atitudes tais como "não aceito receber ordens de uma mulher" (COELHO, 2006) criando barreiras de cunho machista contra a trabalhadora feminina e dificultando o acesso delas às informações. Sendo assim, o acesso à informação em menor proporção pelas mulheres produz decisões mal alicerçadas e desempenhos desastrosos prejudicando o desenvolvimento organizacional. Neste contexto, a insuficiência de informação pode ser listada como uma composição da barreira invisível do teto de vidro, pois, este fator impeditivo "[...] atua na rigidez e no fechamento da estrutura das 
hierarquias organizacionais" (CAPPELLIN, 2008, p. 68), especificamente no que diz respeito à estrutura informal, gerando a existência do teto de vidro dentro das organizações.

Sendo assim, considerando o desenvolvimento do tema, percebeu-se a necessidade de investiga-lo na região de Marília/SP. Desse modo, a pergunta central foi: o teto de vidro é um fenômeno associado à ausência de acesso à informação pelas mulheres? Assim, o cunho desta pesquisa é identificar se existem empecilhos ao acesso à informação e que dificultam a mobilidade das mulheres nos âmbitos corporativos.

Portanto, a investigação justifica-se ao contribuir com uma compreensão sobre os efeitos do não acesso à informação no percurso laboral. Para a execução desta pesquisa exploratória e descritiva, adotou-se como procedimentos metodológicos, a aplicação de questionários estruturados no formato da escala de Likert, possibilitando identificar a percepção de 17 participantes mulheres, as quais foram escolhidas atendendo ao critério de exercerem ou já terem exercido cargos hierárquicos em organizações.

\section{A SUB-REPRESENTAÇÃO DAS MULHERES EM CARGO DE LIDERANÇA}

A incorporação das mulheres no mercado de trabalho ocorre de forma desigual, em diversos setores econômicos. $\mathrm{Na}$ sociedade moderna, a inserção destas trabalhadoras acontece por meio da "[...] divisão sexual horizontal do mercado de trabalho", no qual, a entrada maciça das mulheres é concentrada em atividades específicas, em razão do papel social tradicional atribuído a elas (YANNOULAS, 2002, p. 16).

Por outro lado, nas atividades que requerem maiores responsabilidades e salários, notase que existe uma ausência da ocupação das mulheres. De acordo, com pesquisa de Noland, Moran e Kotschwar (2016) baseada na investigação de 21.980 empresas de 91 países revela que ocorre um baixo domínio de mulheres que exercem trabalhos de liderança. Os autores ainda comentam que menos de $5 \%$ das empresas entrevistadas possuem mulheres como diretora executiva (CEO) e, quase $60 \%$ contam com mulheres como membros de conselhos administrativos.

No Brasil, o estudo do Instituto Ethos (2010) busca conhecer sobre as desigualdades internas das organizações brasileiras. Tal pesquisa contou com 1.506 pessoas que ocupavam o quadro executivo, 13.892 na gerência, 26.034 na supervisão, chefia ou coordenação e 582.528 no quadro funcional. Com relação ao quadro executivo, do total da amostra 86,3\% desses cargos são ocupados por homens (1.299 diretores), sendo que apenas 13,7\% do quadro 
executivo é ocupado por mulheres. Na gerência 22,1\% são mulheres (3.077 mulheres) e 77,9\% são homens (10.815 homens), 26,8\% das mulheres exercem atividades de liderança nos cargos de supervisão, sendo que, 73,2\% são supervisores homens. Nesse sentido, a investigação do Instituto mostra que quanto maior for o nível do cargo, menor é a quantidade de mulheres ocupando tais posições. Em 2015, o Instituto Ethos aplicou novamente esta pesquisa nas organizações brasileiras. Desse modo com os novos dados, 13,6\% das executivas estavam inseridas no quadro executivo, sendo que, $86,4 \%$ dos homens representavam a diretoria das organizações entrevistadas.

A sub-representação das mulheres nos postos de liderança, apontada nas pesquisas do Instituto Ethos (2010, 2015) e pelos autores Noland, Moran e Kotschwar (2016) refere-se à segregação hierárquica, ou "[...] pirâmide ocupacional baseada em gênero", segundo o qual, as mulheres contam com poucas oportunidades de mobilidade profissional dentro das empresas (YANNOULAS, 2002). Trazendo a evidência da exclusão das trabalhadoras femininas na medida que aumenta o acesso a maiores salários e responsabilidades. Em diversas investigações (STEIL, 1997; BOTELHO; MACEDO; FIALHO, 2010; BERNARDI; NEVES, 2015;

CAPELLIN, 2008) a segregação hierárquica é conhecida como Glass Ceiling, ou Teto de vidro, sendo uma barreira invisível que interrompe o crescimento profissional das mulheres dentro da estrutura organizacional.

\section{GLASS CEILING: ORIGEM DO CONCEITO}

O termo Glass Ceiling foi mencionado pela primeira vez em 1986, no contexto de crises das "relações contratuais estáveis", acrescido pelo cenário de "exclusão/inclusão" (CAPPELLIN, 2008). Este contexto fez com que dois jornalistas do Wall Street Journal investigassem a ascensão profissional das mulheres dentro das organizações americanas, na década de oitenta. Esta pesquisa, tinha como cunho estudar a inserção das mulheres nas relações de trabalho. Para os jornalistas, especialmente na década de oitenta houve uma volumosa incorporação de trabalhadoras, em que “[...] as mulheres foram por vontade e não pela necessidade de um período entre e pós-guerra" (BOTELHO; MACEDO; FIALHO, 2010, p. 5). Os postos assumidos concentravam-se apenas em cargos de baixa qualificação e remuneração, sendo os demais ocupados pelos trabalhadores homens. Os jornalistas passaram a se questionar porque as mulheres estavam apenas na base da pirâmide organizacional e não no topo da hierarquia, uma vez que elas se apresentavam em grande quantidade nas nas empresas 
(FLETCHER, 2004). Logo a explicação para esta segregação vertical, foi publicada no artigo The glass ceiling: why women cant seem to break the invisible barrier that blocks them from the top jobs, cujo os autores eram Hymowtz e Schillhardt (1986) (BOTELHO; MACEDO; FIALHO, 2010, p. 6). Para eles:

[...] ao investigarem o mundo corporativo, descobriram que o acesso das mulheres em direção ao topo de suas carreiras estava diretamente ligado não só a cultura da sociedade, mas também, fortemente representada pela cultura corporativa de suas organizações (BOTELHO; MACEDO; FIALHO, 2010, p.6).

De modo geral, após a publicação dos jornalistas o teto de vidro passou a ser conhecido como uma barreira invisível que é forte o suficiente para interromper a ascensão profissional das mulheres na estrutura organizacional (BAXTER; WIGTH, 2000). Ou seja, as mulheres conseguem visualizar os cargos acima do teto de vidro, porém a linha imaginária da barreira invisível as impede de chegar até eles.

As mulheres são numericamente a maior população que acessa o ensino superior, chegando a uma média de 11 anos de estudo. De acordo com o Instituto Ethos (2010), enquanto os diretores homens representam $86,4 \%$ das diretorias, sendo $96,7 \%$ destes com formação superior, as mulheres representam 13,7\% da cúpula organizacional, $99 \%$ delas com nível de educação superior. Todavia, mesmo que elas possuam formação superior, o teto de vidro "parece pôr-lhe freios" (CAPPELLIN, 2008), indicando a sua existência, dentro dos espaços corporativos.

Outro exemplo da força do teto de vidro está no setor público, pois, segundo Vaz (2013), mesmo que este setor esteja propício a adotar metodologias de contratação mais transparentes, as mulheres ainda continuam dominando os cargos públicos de menor responsabilidade, uma vez que é na "[...] administração pública federal, onde se observa uma representatividade feminina decrescente à medida que se avança nos níveis hierárquicos dos cargos do grupo DAS".

\section{AS BARREIRAS DO TETO DE VIDRO}

As barreiras invisíveis do teto de vidro se constituem de preconceitos contra as mulheres e ocorrem em comportamentos, atitudes e formas de pensar enraizados na cultura organizacional. Neste sentido, o Glass Ceiling não se resume a uma simples barreira, mas sim na existência de artifícios que "[...] atuam na rigidez e no fechamento da estrutura das 
hierarquias organizacionais" (CAPPELLIN, 2008).

Desse modo, Betiol e Tonelli (1991) comentam que como as estruturas hierárquicas são mais estreitas para as trabalhadoras, não há um caminho para elas. Sendo assim, para aquelas que conseguem perceber uma possibilidade de alcaçar a liderança por trás do teto de vidro, acabam adotando um perfil de executiva cujas características são mais masculinas (CARVALHO NETO; TANURE; ANDRADE, 2010).

Além disso, Betiol e Tonelli (1991) explicam que a responsabilidade títpica da liderança ainda é atribuída e monopolizada por homens, isto é, para que as mulheres consegam ocupar este âmbito é preciso "[...] ser um homem", adaptando-se as exigências da cultura corporativa.

Outra evidência do teto de vidro é a rede de contatos, ou mais conhecida como networking, estratégica para aqueles que almejam ascender profissionalmente dentro da organização, pois fortalece e cultiva relações profissionais, seja para crescer na carreira, ou para consolidar negociações. Desta forma, o networking é uma barreira, pois as mulheres costumam ser menos incluídas na relação de contatos de trabalho. Isto acarreta em uma formação escassa para a construção de "[...] novas competências, a falta de modelos e a ausência de um mentor na sua carreira" (MANGANELLI, 2012).

Outros autores listam como uma barreira do teto de vidro a mobilidade geográfica (CARVALHO NETO; TANURE; ANDRADE, 2010; BETIOL; TONELLI, 1991). Uma vez que, as mulheres sentem dificuldade em se deslocar quando surge uma viagem de negócios, situação que se agrava se a trabalhadora feminina tiver um conjugue. Para Betiol e Tonelli (1991) "[...] a mulher, habitualmente, não desloca o marido e os filhos em função da demanda da empresa”. Desta forma, a família se constitui em uma das razões que são impeditivas para as mulheres alcançarem mobilidade profissional nos espaços corporativos.

Além disso, Steil (1997) comenta que o menor comprometimento das mulheres com a organização é considerado como um fator que dificulta a chegarem na liderança. Para a autora, este é um fator importante para entender o teto de vidro, pois:

Sua importância baseia-se no fato de que, na realidade, poucos executivos homens admitem rejeitar uma mulher em função de seu gênero e, também, poucos discordam sobre mulheres poderem oferecer importantes habilidades gerenciais. Entretanto, em seus gabinetes, preocupam-se com o aspecto de as organizações investirem tempo e recursos financeiros para treinar uma mulher para depois vê-la casar-se, engravidar e deixar a organização (STEIL, 1997, p. 64).

A suposta falta de comprometimento organizacional, faz com que as empresas tenham 
menor intenção em contratar mulheres para postos de liderança, deixando à mostra, a subrepresentação delas na cúpula organizacional.

Por outro lado, outra barreira do teto de vidro é refletida nos preconceitos com as mulheres por parte dos colaboradores. Como explicam Betiol e Tonelli (BETIOL; TONELLI, 1991) o ambiente corporativo ainda é dominado por homens, de forma que, quando uma mulher ocupa este cargo os funcionários da organização podem ter resistência em ser liderados por uma executiva.

Como consequência, esta resistência pode provocar a criação de barreiras de cunho machistas contra as trabalhadoras, dificultando o acesso delas às informações, cujo resultado produz decisões mal alicerçadas e desempenhos desastrosos prejudicando o desenvolvimento organizacional. Como exemplo, destaca-se a história real contada no filme Estrelas além do tempo (2016), no qual aborda-se sobre a inserção das mulheres negras nas operações tecnológicas da NASA, um ambiente monopolizado por homens na época. Em uma das passagens do filma Katherine Johnson (Taraji P. Henson) é recrutada para ser uma calculadora humana em uma das operações da NASA, a qual rodeada por homens e por algumas colegas mulheres, tinha a missão de realizar cálculos que auxiliassem na corrida espacial travada entre os Estados Unidos e a Rússia. O filme retrata que Katherine impedida de acessar informações (que estavam cobertas por uma tinta preta) contidas nos documentos entregues a ela por seu 'colega de trabalho'. O não acesso à informação inviabilizava um trabalho bem-sucedido e rápido.

Por fim, ressalta-se que o teto de vidro é um mecanismo cultural e social, e por isso, resvala em processos de liderança e na comunicação, de forma que a informação não acessada gera prejuízo para a organização e não apenas para a trabalhadora. Os preconceitos e a marginalização devem ser excluídos do ambiente laboral, construindo uma cultura organizacional que reflita mulheres em igualdade de acesso à informação, quando comparadas aos homens.

\section{RESULTADOS E ANÁLISES}

Para verificar a percepção das mulheres sobre a questão problemática proposta, realizou-se uma pesquisa cujos resultados seguem os parâmetros:

Quadro 1: Interpretação da Escala de Likert

\begin{tabular}{l|l|l|}
\cline { 2 - 3 } & Escala de Likert & Valor \\
\cline { 2 - 3 } & Discordo totalmente & 1,0 a 1,5 \\
\hline
\end{tabular}

Complexitas - Rev. Fil. Tem., Belém, v. 3, n.1 , p. 60-75, jan.jun. 2018 - ISSN: 2525-4154 


\begin{tabular}{|l|l|}
\hline Discordo parcialmente & 1,6 a 2,5 \\
\hline Indiferente & 2,6 a 3,5 \\
\hline Concordo parcialmente & 3,6 a 4,5 \\
\hline Concordo totalmente & 4,5 a 5,0 \\
\hline
\end{tabular}

Fonte: elaborado pelas autoras.

Quadro 2: Classificação do Coeficiente de Variação

\begin{tabular}{|l|l|}
\hline $\begin{array}{l}\text { Coeficiente de } \\
\text { Variação }\end{array}$ & Dispersão \\
\hline $0 \% \leq \mathrm{CV} \leq 15 \%$ & Muito baixa \\
\hline $16 \% \leq \mathrm{CV} \leq 30 \%$ & Baixa \\
\hline $31 \leq \mathrm{CV} \leq 70 \%$ & Moderada \\
\hline $\mathrm{CV}>70 \%$ & Alta \\
\hline
\end{tabular}

Fonte: elaborado pelas autoras.

Os resultados obtidos com a coleta de dados indicam que a média de idade das mulheres participantes da pesquisa é de 42,7 anos. Além disso, 8 possuem pós-graduação, 8 possuem o ensino superior e apenas uma o ensino médio. A média de tempo de experiência de trabalho é de 16,8 anos, porém com uma notável variação, sendo que para uma delas é de 38 anos, enquanto para outra é de apenas 4 meses.

As demais afirmativas foram concentradas em um quadro, juntamente com a Média Ponderada (MP) e o Coeficiente de Variação (CV) das respostas.

Quadro3: Resultado das informações coletadas

\begin{tabular}{|c|c|c|}
\hline & MP & CV \\
\hline 1- Não tenho acesso a informação que preciso para desempenhar meu trabalho. & 1,5 & 68,8 \\
\hline 2 - Tenho dificuldade de acessar a informação que preciso em meu trabalho. & 1,5 & 68.8 \\
\hline 3 - Sou excluída de conversas paralelas e informais onde trabalho. & 1,88 & 72,53 \\
\hline 4 - A interação com os colegas em meu trabalho é insuficiente. & 2,25 & 64 \\
\hline 5 - Meu trabalho exige que eu compartilhe informação. & 4,71 & 16,3 \\
\hline 6 - Onde trabalho a informação está inacessível. & 1,44 & 56,63 \\
\hline 7 - Não sei onde buscar a informação que preciso. & 1,06 & 22,88 \\
\hline 8 - Falta clareza na informação que chega a mim. & 2,06 & 65,29 \\
\hline $\begin{array}{l}9 \text { - A informação é mais valorizada na organização/empresa quando é compartilhada } \\
\text { por um colega (homem). }\end{array}$ & 2 & 63,74 \\
\hline 10 - Sou discriminada em meu trabalho porque sou mulher. & 1,47 & 68,63 \\
\hline $\begin{array}{l}11-\text { A empresa/organização onde trabalho possui “chefes” (superiores hierárquicas) } \\
\text { mulheres. }\end{array}$ & 4,35 & 33,45 \\
\hline $\begin{array}{l}12 \text { - Onde trabalho não há diferença entre a participação de homens e de mulheres no } \\
\text { compartilhamento de informação. }\end{array}$ & 4 & 38,5 \\
\hline 13 - A linguagem (termos) utilizada na comunicação da organização onde trabalho é de & 1,59 & 59,13 \\
\hline
\end{tabular}




\begin{tabular}{|l|c|c|}
\hline difícil entendimento. & & \\
\hline $\begin{array}{l}14-\text { Tenho amigos homens no trabalho, com os quais compartilho informação e } \\
\text { experiências. }\end{array}$ & 4,71 & 1,25 \\
\hline 15 - Busco ajuda e informação com meus colegas e superiores (“chefes") homens. & 4,71 & 14,56 \\
\hline 16 - A falta de acesso à informação já me prejudicou no trabalho. & 3 & 51,33 \\
\hline 17 - A falta de acesso à informação influencia em meu desempenho. & 3,47 & 40,89 \\
\hline $\begin{array}{l}18-\text { A falta de acesso à informação me impede ou impediu de acessar cargos de } \\
\text { "chefia". }\end{array}$ & 2,18 & 69,39 \\
\hline 19 - A dificuldade de acessar a informação ocorria apenas no início de minha carreira. & 2,59 & 56,41 \\
\hline 20 - Os colegas de trabalho homens me tratam sem preconceito e como parte do grupo. & 4,06 & 31,97 \\
\hline
\end{tabular}

Fonte: elaborado pelas autoras -2018.

Assim, entre as afirmativas propostas no instrumento destaca-se a 19, na qual a intenção era verificar se a dificuldade de acessar a informação ocorria apenas no começo da carreira. A percepção repassada pelas respondentes aponta para a neutralidade, significando que nem concordam e nem discordam sobre as dificuldades ainda permanecerem quanto ao acesso à informação, com um RM de 2,59. Contudo, como apresentaram um CV 56,41\%, nota-se que não há consenso sobre a resposta à afirmativa, o que significa que existe CV moderado.

Outro destaque nos resultados foi sobre a afirmativa 1, na qual a MP foi 1,5, enquanto o CV ficou em 68\%, portanto com uma variação moderada. Nesse caso, também não há um consenso, pois, as respondentes indicaram respostas diferentes, isto é, para algumas, há acesso à informação para que desempenhem o trabalho, enquanto para outras esse acesso não se concretiza.

Já no que diz respeito à afirmativa 3, na qual a intenção era questionar se eram excluídas de conversas paralelas e informais onde trabalham, a MP indicou que discordam parcialmente, e o CV foi alto. Uma interpretação para isso é que algumas se posicionam mais favoráveis à afirmativa, mostrando que isso pode acontecer, porém se sobressaindo que discordam, ou seja, que não são excluídas das conversas informais.

Demonstraram nas respostas que sabem que o trabalho exige que compartilhem informação, para as participantes a informação no trabalho está acessível, discordam que são discriminadas, bem como discordam sobre o fato de faltar informação impedir que cheguem a cargos de chefia. Por outro lado, sinalizaram que a falta de acesso à informação influencia (negativamente) no desempenho no trabalho, e afirmaram que compartilham informação com colegas homens.

Contudo, apesar das medidas estatísticas aplicadas não apresentarem resultados 
coincidentes com a literatura, algumas contradições puderam ser verificadas nas respostas dissertativas, entre as quais: elas indicam acreditar que existem preconceitos com relação às mulheres que ocupam cargos de liderança; além disso que uma parte das pessoas, independentemente de serem homens ou mulheres, não estão capacitados emocionalmente e eticamente para exercerem tal função; também pontuaram que a mulher precisa provar a todo momento a sua capacidade, inclusive demonstrando que é superior a qualquer outro homem, o que leva à não poderem cometer erros. Nesse sentido, nas respostas dissertativas fica claro que a exclusão ocorre de forma velada, situação percebida em momentos em que a mulher é excluída de conversas.

Nota-se que o preconceito não está localizado apenas na percepção do homem, podendo surgir também em mulheres. Uma das respostas expressa esse descontentamento com os maltrato voltados às mulheres: "Essas práticas são comuns nos setores onde trabalhei e sempre quando eu denunciava a atitude antidemocrática e sem transparência era excluída, me tornava "persona non grata" e sofria toda sorte de perseguições e maledicências fossem ou não frontais". Outras respostas indicam que além de práticas de humilhação e marginalização verbalizadas, práticas direcionadas para eliminar a vida de uma das participantes. Também é importante destacar entre as respostas que a mulher, para conseguir posições de destaque também acaba optando por sacrifícios pessoais e que muitos homens não precisam fazer o mesmo.

\section{CONSIDERAÇÕES FINAIS}

A questão central da presente pesquisa era investigar se o não acesso à informação tem relação com o teto de vidro. A literatura indica que sim, uma vez que uma parte das estratégias usadas como barreiras residem no fato de excluir a mulher da comunicação informal, não permitindo que esta participe do "clube do bolinha", cujos resultados são sentidos diretamente nos fluxos de informação. Por outro lado, a pesquisa não conseguiu resultados compatíveis com o que sugere a literatura. Uma explicação para isso pode estar na escolha das participantes à pesquisa, pois todas elas já possuem cargos de liderança e, com barreiras de menor impacto vivenciadas por estas mulheres, uma vez que possuem alto nível de formação e preparo. Uma segunda explicação pode estar no perfil destas mulheres. Mesmo não se tendo investigado os traços de personalidade e os valores que governam o comportamento delas, pode-se recorrer à literatura para obter uma explicação. Nesse sentido, é possível que tenham características mencionadas pela literatura como serem mais masculinizadas em suas posturas, o que poderia 
minimizar os efeitos do teto de vidro, e inclusive da barreira do não acesso à informação. Desse modo, mais pesquisas devem ser realizadas sobre o não acesso à informação como uma das barreiras que compõe o teto de vidro, investigando se no contexto da região de Marília, as trabalhadoras que não conseguiram conquistar cargos mais elevados hierarquicamente possuem a mesma percepção sobre o que foi defendido como uma das barreiras, o não acesso à informação. Portanto, falta clareza por parte das participantes de que a exclusão da comunicação é uma discriminação e uma barreira às trabalhadoras.

Por fim, há que se considerar também a naturalização da condição da mulher na sociedade e das barreiras que lhe são impostas, não apenas por homens, mas inclusive por outras mulheres. Essa situação pode interferir na maneira como as participantes percebem o tema, podendo produzir a aceitação das barreiras ou ainda, podendo a leva-las a não perceber a presença dos impedimentos e do isolamento.

Diante da discussão proposta, recupera-se de uma pesquisa sobre o teto de vidro realizada no contexto africano, a seguinte afirmação:

Um velho ditado diz que se você acha que o conhecimento não é importante, tente a ignorância. Um estado de não saber é aquele que não é desejável para ninguém e é mais devastador quando uma mulher não sabe. Isso porque é mais provável que ela transfira sua ignorância para seus descendentes e daí resulta mais mulheres e homens ignorantes (OYELUPE, 2012, p.2).

Isto é, o não acesso não afeta apenas as mulheres, podendo prejudicar homens e as organizações onde elas atuam.

\section{REFERÊNCIAS BIBLIOGRÁFICAS}

AKPINAR-SPOSITO, Cansu. Career barriers for women executives and the glass ceiling syndrome: the case study comparison between french an Turkish women executive. Procedia - Social and Behavioral Scie nces, v.75, p.488497, 2013.

ARAÚJO, Carlos Alberto Ávila. Fundamentos da ciência da informação: correntes teóricas e o conceito de informação. Perspectivas em Gestão \& Conhecimento, João Pessoa, v. 4, n. 1, p. 57-79, jan./jun.

2014.
BARROS, Maria Helena T. C. Disseminação da informação: entre a teoria e a prática. Marília, 2003.

BAXTER, J.; WRIGHT, E. O. The glass ceiling hypothesis a comparative study of the United States, Sweden, and Australia. Gender \& Society, vol. 14, n. 2, April 2000.

BERNARDI, Renato; NEVES, Raquel Cristina. As garantias constitucionais à igualdade de gênero e a realidade do "teto de vidro" para a mulher trabalhadora. Revista do Direito Público. Londrina, v.10, n.2, p.167-186, mai./ago. 2015. 
BETIOL, M. I. S; TONELLI, M. J. As mulheres executivas e suas relações de trabalho. RAE-revista de administração de empresas, v. 31, n. 4, p. 17-33, 1991.

BOTELHO, Louise de Lira Roedel; MACEDO, Marcelo; FIALHO, Francisco Antônio Pereira. "Glass Ceiling” em empresas intensivas em conhecimento: desafios enfrentados por executivas em suas ascensões profissionais. XXX Encontro

Nacional de Engenharia de Produção, São Carlos, São Paulo, out. 2010.

CAPELLIN, Paola. As desigualdades impertinentes: telhado, parede ou céu de chumbo? Niterói, v. 9, n. 89, p. 89126, sem. 2008.

CARVALHO NETO, A. M.; TANURE, B.; ANDRADE, J. Executivas: carreira, maternidade, amores e preconceito. ERA- revista de administração de empresas, v. 9, n. 1, 2010.

COELHO, Danilo. Ascensão profissional de homens e mulheres nas grandes empresas brasileiras. Disponível em: < http://www.en.ipea.gov.br/agencia/imag es/stories/PDFs/livros/Cap_6.pdf >. Acesso em: 28 maio 2018

CORRÊA, Vanisse Simone Alves. $O$ fenômeno do "telhado de Vidro": elementos determinantes do acesso feminino aos cargos superiores na educação. Disponível em: < http://www.anpae.org.br/congressos_art igos/simposio2009/350.pdf >. Acesso em: 28 maio. 2018.

DANTAS, Willy Macedo de. A tecnologia $e$ a informação na construção de valores de responsabilidades social. Dissertação (Mestrado em Ciência da Informação) Programa de Pós-Graduação em Ciência da Informação - Faculdade de Filosofia e Ciências - Unesp/Marília, 2006.
FADEL, Bárbara et al. Gestão, mediação e uso da informação. Marta Valentim (org.) - São Paulo: Cultura Acadêmica, 2010.

FLETCHER, Joyce K. The Paradox of Post Heroic Leadership: An Essay on Gender, Power and Transformational Change. The Leadership Quarterly, v.15, p.647-661, 2004.

INOMATA, Danielly Oliveira; VARVAKIS, Gregório. Fluxos de informação no desenvolvimento de produtos biotecnológicos. Curitiba: Appris, 2016.

JAMON, Lori J. Cracking the glass ceiling: a phenomenological study of women administrators in higher education. 2014. Tese (Doutorado em Filosofia) - Iwoa State University, Iowa.

MANGANELLI, A. A mão invisível do teto de vidro. Porto Alegre, 2012. 123f. Dissertação (Mestrado em Economia) Programa de Pós-Graduação em Economia do Desenvolvimento Faculdade de Administração, Contabilidade e Economia, PUCRS.

NOLAND, M.; MORAN, T.;

KOTSCHWAR, B. Is gender diversity profitable? Evidence from a global survey. In: Peterson Institute for International Economics.

OYELUPE, Adetoun A.; BAMIGBOLA, Alice A. Women empowerment through access to information (ATI): the strategic roles of non-governmental organizations in Nigeria. World Library and Information Congress: 78th IFLA General Conference and Assembly. 2012. p.118.

PAES, Bárbara. Acesso à informação e direitos das mulheres. São Paulo: Artigo 19 Brasil, 2016. Disponível em: 
http://artigo19.org/wp-

content/blogs.dir/24/files/2016/12/Aces

so-\%C3\% A0-

Informa\%C3\% A7\%C3\%A3o-e-

Direitos-das-Mulheres.pdf. Acesso em:

28 de abril de 2018.

ROCHA, C. D.; SILVA, G. R. d.; SÉ, V. A. d.; FLORIANO, V. A. S. d.; MELO, F. A. O. d.. O fenômeno teto de vidro na ascensão hierárquica das mulheres no mercado formal: barreiras. SEGeT, XI Simpósio de Excelência em Gestão e Tecnologia, 2014.

STAREC, Claudio (Org.). Gestão da informação, inovação e inteligência competitiva: como transformar a informação. São Paulo: Saraiva, 2012.

STEIL, Andrea Valéria. Organizações gênero e posição hierárquicacompreendendo o fenômeno do teto de vidro. Revista de Administração, São Paulo, v. 32, n. 3, p. 62-69, jul./set. 1997.

VIAPIANA, Claúdio. Fatores de sucesso e fracasso da micro e pequena empresa. Anais do II EGEPE, Londrina/PR, nov. 2001. Disponível em:

http://www.anegepe.org.br/edicoesanter iores/londrina/GPE2001-14.pdf >. Acesso em: 11 maio. 2018.

YAFUSHI, Cristiana Aparecida Portero. Competência em informação para a construção de conhecimento no processo decisório: estudo de caso na Duratex de Agudos (SP). Dissertação (Mestrado em Ciência da Informação) Universidade Estadual Paulista, Faculdade de Filosofia e Ciências, 2015.

VAZ, Daniela Verzola. O teto de vidro nas organizações públicas: evidências para o Brasil. Economia e Sociedade, Campinas, v. 22, n.3 (49), p. 765-790, dez. 2013.

YANNOULAS, Silvia Cristina. Dossiê: Políticas Públicas e relações de gênero no mercado de trabalho. Brasília (DF): CFEMEA; 2002. Disponível em: http://www.bibliotecadigital.abong.org. br/bitstream/handle/11465/276/CFEME A_Dossi\%EA_Pol\%EDticas_p\%FAblic as_rela\%E7\%F5es_g\%EAnero_mercad o_trabalho.pdf?sequencs $=1$. Acesso em: 10 de abril de 2018.

OLIVEIRA, B.B.; WOIDA, L.M. O Fenômeno Glass Ceiling e o Acesso à Informação: Estudo Sobre Barreiras Invisíveis Impostas às Mulheres no Trabalho. Complexitas - Rev. Fil. Tem. Belém, v. 3, n. 1, p. 61-75, jan./jun. 2018. Disponível em:< http://www.periodicos.ufpa.br/index.php/complexitas/article/view/6636>. Acesso em: 20 de fevereiro de 2019. 